\title{
约 \\ A POLÍTICA DE COMUNICAÇÃO COMO INSTRUMENTO ESTRATÉGICO DE GESTÃO PARA O PARLAMENTO BRASILEIRO
}

\author{
COMMUNICATION POLICY AS AN INSTRUMENT STRATEGIC MANAGEMENT \\ INSTRUMENT FOR THE BRAZILIAN PARLIAMENT
}

\section{LA POLÍTICA DE COMUNICACIÓN COMO INSTRUMENTO ESTRATÉGICO DE GESTIÓN PARA EL PARLAMENTO BRASILEÑO}

Wilson Costa Bueno ${ }^{1}$

\begin{abstract}
Resumo: A interação com os públicos estratégicos do Parlamento brasileiro tem como características básicas a complexidade e a diversidade de perfis e deve ser respaldada em uma Política de Comunicação, com diretrizes, princípios, ações e estratégias bem definidas a serem assumidas por todos os seus representantes. $\mathrm{O}$ artigo, respaldado em revisão bibliográfica que contempla, sobretudo, os conceitos de política de comunicação e de comunicação pública, resgata cases brasileiros de políticas de comunicação em empresas e organizações (em especial institutos federais e universidades públicas), propõe uma metodologia para a construção de uma Política de Comunicação para o Parlamento brasileiro.
\end{abstract}

Palavras-chave: Política de Comunicação; Comunicação Pública; Parlamento Brasileiro; Comunicação Organizacional; Interesse Público.

\begin{abstract}
The interaction with the strategic audiences of the Brazilian Parliament has as its basic characteristics the complexity and diversity of profiles and must be supported by a Communication Policy, with well-defined guidelines, principles, actions and strategies to be assumed by all its representatives. The article, supported by a bibliographic review that mainly contemplates the concepts of communication policy and public communication, rescues Brazilian cases of communication policies in companies and organizations (in particular federal institutes and public universities), proposes a methodology for the construction of a Communication Policy for the Brazilian Parliament.
\end{abstract}

Keywords: Communication Policy; Public Communication; Brazilian Parliament; Organizational Communication; Public Interest.

Resumen: La interacción con las audiencias estratégicas del Parlamento brasileño tiene como características básicas la complejidad y diversidad de perfiles y debe ser apoyada por una Política de Comunicación, con lineamientos, principios, acciones y estrategias bien definidas para ser asumidas por todos sus representantes. El artículo, apoyado en una revisión bibliográfica que contempla principalmente los conceptos de política de comunicación y comunicación pública, rescata casos brasileños de políticas de comunicación en empresas y organizaciones (en particular institutos federales y universidades públicas), propone una metodología para la construcción de una Política de Comunicación para el Parlamento brasileño.

Palabras clave: Política de Comunicación; Comunicación Pública; Parlamento Brasileiro; Comunicación Organizacional; Interés Público.

\footnotetext{
${ }^{1}$ Professor Sênior da Escola de Comunicações e Artes da Universidade de São Paulo (USP). Diretor da Comtexto Comunicação e Pesquisa, empresa de consultoria nas áreas de Comunicação Organizacional e Jornalismo Especializado.E-mail: professor@ comtexto.com.br
} 


\section{Introdução}

A comunicação organizacional brasileira tem experimentado mudanças significativas no século XXI em função de um conjunto abrangente de fatores, notadamente aqueles que dizem respeito ao impacto das novas tecnologias de comunicação e informação, à emergência de novos paradigmas nos sistemas de gestão e ao protagonismo crescente dos públicos estratégicos.

Este novo cenário requer a consolidação de uma nova práxis comunicacional que assume como pressupostos básicos a complexidade do relacionamento das empresas e organizações de maneira geral com os seus públicos estratégicos e, obrigatoriamente, a sua condição de processo integrado e estratégico.

Diferentemente do modelo conservador que vigorou em décadas passadas, a comunicação assume um novo ethos, superando uma perspectiva essencialmente operacional ou tarefeira com a qual esteve identificada por um longo tempo. A estrutura profissionalizada de comunicação ganha destaque no organograma das organizações, aprofunda a sua articulação com os demais setores (planejamento estratégico, tecnologia da informação, gestão de pessoas, dentre outras). Além disso, relação intrínseca entre comunicação e a cultura organizacional fica explicitada e há um esforço permanente para alinhar as ações e estratégias de comunicação com os objetivos e os valores institucionais.

O ritmo frenético das mídias sociais, que têm merecido adesão crescente dos públicos estratégicos e da sociedade de maneira geral, o ativismo e a capacidade de mobilização de grupos organizados comprometidos com causas e movimentos sociais relevantes incorporam novos desafios ao planejamento e execução da comunicação organizacional, aos quais se somam a necessidade de responder com rapidez, quase instantaneamente, às demandas por informações e à pluralidade de vozes, muitas vezes situadas em dimensões distintas e antagônicas.

A ampliação do uso de tecnologias disruptivas no universo da comunicação tem potencializado oportunidades e riscos, merecendo, por isso, avaliações sistemáticas da relação custo $\mathrm{x}$ benefício comumente associada às suas inúmeras aplicações.

Merece ser destacado, nas primeiras décadas deste século, o desenvolvimento de utilizações pioneiras, em vários campos, inclusive da comunicação, da inteligência artificial (IA) e de estratégias de Data Analytics (inteligência analítica).

A possibilidade de identificar padrões significativos pela análise e cruzamento de volumes formidáveis de dados e informações, com o objetivo de subsidiar processos competentes de tomada de decisões, revoluciona o mundo dos negócios e da administração pública e tem implicações importantes também na comunicação.

$\mathrm{O}$ crescimento exponencial dos dados e informações em circulação tem requerido, das empresas e organizações, soluções complexas para os processos de armazenamento, análise e comunicação, que, se bem gerenciadas, permitem o desenvolvimento de ações e estratégias inovadoras nos campos do marketing e da comunicação organizacional. 
A inteligência artificial (IA), o aprendizado de máquina, comumente entendido como um subcampo da IA (ou da ciência da computação), e os mecanismos de Data Analytics, enquanto processos articulados, prometem efetivamente disrupções nos modelos atualmente adotados na forma de produzir e receber informações, mas são percebidos também como potenciais ameaças.

A comunicação organizacional, como processo estratégico que ocupa lugar de destaque na chamada economia do conhecimento, deverá incorporar, obrigatoriamente, essas novas tecnologias, com efeitos ainda não totalmente previsíveis para o debate democrático e a afirmação da cidadania.

As novas tecnologias de informação e comunicação, em particular as mídias sociais, têm favorecido a aceleração do processo de produção e circulação de informações não confiáveis e incorporados, por isso, novos desafios à comunicação organizacional, pública ou privada.

O processo de relativização da verdade ou de desinformação, que caracteriza o chamado universo da pós-verdade (concebido como aquele no qual as emoções e crenças pessoais valem mais do que os fatos objetivos), gera o caos informativo, com consequências nefastas, sobretudo em momentos de crise, como o da covid-19, para o esclarecimento dos cidadãos e mesmo o desenvolvimento adequado de políticas públicas. Movimentos que propõem a rejeição a processos legítimos e indispensáveis (como o que mobiliza as pessoas contra a vacinação) e campanhas alimentadas por bots que afrontam a reputação de pessoas e organizações, ou ameaçam autoridades, são cada vez mais comuns e confundem os cidadãos.

A comunicação organizacional, pública e privada, tem sido penalizada por esta avalanche incontrolável de informações falsas, que contribui para provocar tensões institucionais e mesmo para degradar a imagem de empresas e organizações de maneira geral. Será necessário, cada vez mais, e de forma permanente, que a comunicação organizacional esteja comprometida com o processo de conscientização e mobilização dos públicos estratégicos, internos ou externos, para enfrentar esse fenômeno contemporâneo. Mais ainda, deve implementar ações adequadas para a checagem dos fatos e para os riscos do compartilhamento de informações inverídicas.

A consolidação da comunicação organizacional como processo requer, também, esforço importante para o desenvolvimento de métodos e técnicas para a avaliação sistemática das ações, estratégias e produtos, com a elaboração de indicadores e métricas competentes para mensurar a sua eficácia.

\section{A Política de Comunicação}

O conjunto destes fatores, obrigatoriamente, passa a exigir das empresas e organizações uma mudança dramática de postura em termos de planejamento da sua comunicação, de modo a superar uma perspectiva tradicional que privilegia o feeling dos seus executivos. Na prática, isso significa respaldar suas ações e estratégias de comunicação em um conjunto sistematizado e competente de diretrizes gerais e específicas de comunicação que possam orientar o seu 
relacionamento com os públicos estratégicos.

Este documento de gestão, denominado de Política de Comunicação, ainda não está presente na maioria das organizações brasileiras, mas é fácil perceber que tem havido um esforço louvável, sobretudo na área pública, de construí-lo, a partir de um processo dialógico que mobiliza os seus públicos internos.

Simplificadamente, podemos definir Política de Comunicação como um conjunto sistematizado de diretrizes, que tem como finalidade orientar o desenvolvimento de ações, estratégias e produtos de comunicação tendo em vista o relacionamento uma organização ou empresa com os seus diversos públicos estratégicos.

A Política de Comunicação está consolidada em um documento-síntese, acessível a todos os públicos internos e externos, e se desdobra em vários produtos (guias, manuais, auditorias e diagnósticos, programas de capacitação) e, sobretudo, em um plano de comunicação, com ações a serem desenvolvidas a curto, médio e longo prazos, que tem como objetivo torná-la efetiva.

A Política de Comunicação está, indissoluvelmente, alinhada com processo de gestão e a cultura organizacional e pressupõe a existência de uma estrutura profissionalizada de comunicação e de recursos (humanos, financeiros, tecnológicos), essenciais para a sua implementação, bem como vontade política e compromisso institucional para colocá-la em prática e viabilizar a obediência às suas diretrizes.

A Política de Comunicação tem como pressupostos básicos: a) a necessidade permanente de sua revisão e atualização; b) a incorporação, em sua proposta, de todos os públicos estratégicos; c) reconhecimento de que a comunicação em uma organização é responsabilidade de todos; d) a sua singularidade.

A Política de Comunicação é realizada em um tempo determinado e, portanto, ela é datada. Isso significa que ela deve ser permanentemente revista e atualizada, visto que os objetivos institucionais podem se modificar ao longo do tempo, assim como se incorporaram novas tecnologias, focos de interesse e estratégias no universo essencialmente dinâmico como o da comunicação organizacional.

É indispensável, na elaboração de uma Política de Comunicação, considerar a multiplicidade de públicos estratégicos, com a avaliação, inclusive, daqueles que são prioritários, tendo em vista o seu impacto na organização ou empresa. Constitui grave equívoco levar em conta apenas os públicos externos (imprensa, investidores, órgãos da sociedade civil, Poderes da República, dentre outros), relegando a um segundo plano os públicos internos (funcionários ou servidores, por exemplo) que são parceiros naturais, responsáveis pelo bom funcionamento da organização.

A Política de Comunicação deve, também, assumir que a comunicação em uma organização não ocorre apenas pela intervenção da estrutura profissionalizada de comunicação, mas que envolve todos os públicos internos que estabelecem fluxos de informação e promovem 
interações com os demais públicos estratégicos. Os comunicadores profissionais exercem atividades especializadas, voltadas para o cumprimento de objetivos específicos (por exemplo, relacionamento com a mídia, edição de veículos ou publicações, gestão das mídias sociais, planejamento e execução de eventos institucionais) mas, não dão conta do conjunto significativo de relacionamentos que uma organização, em sua rotina diária, estabelece com determinados públicos.

Toda Política de Comunicação é, na verdade, uma experiência única, singular, porque ela reflete a trajetória, os princípios, os valores, a visão, a missão de uma determinada organização/empresa que, evidentemente, não se confundem com os atributos de nenhuma outra. Ainda que os vários documentos que definem a Política de Comunicação de uma organização mantenham um roteiro padrão, com a indicação de temas ou capítulos específicos, as diretrizes, as posturas e as estratégias certamente variarão em função de uma série de circunstâncias, visto que toda organização está inserida em um contexto socioeconômico, político e cultural com características específicas.

\section{Política de comunicação: o cenário brasileiro}

A construção de Políticas de Comunicação por organizações ou empresas brasileiras tem crescido, de maneira surpreendente, no século XXI, notadamente na área pública, com destaque especial a universidades, institutos federais e de pesquisa e mesmo empresas públicas.

Considera-se como marco na elaboração de Políticas de Comunicação em nosso país a experiência da Rhodia, empresa do setor químico, que, de forma pioneira, definiu a sua Política de Comunicação na metade da década de 1980, consolidada em um documento denominado Plano de Comunicação Social incluído em obra publicada por Nori e Valente (1990). Na prática, a proposta da Rhodia pode ser considerada híbrida, porque reunia, num mesmo documento, diretrizes, tais como os que caracterizam uma verdadeira Política de Comunicação, e indicação de ações concretas a serem implementadas na relação desta empresa com determinados públicos estratégicos.

Em geral, quando analisamos as Políticas de Comunicação construídas por empresas e organizações brasileiras, podemos identificar dois formatos distintos: a) modelo padrão, que apenas enuncia as diretrizes gerais, os princípios e os valores ou atributos da comunicação, os canais de relacionamento e as principais atividades que irão nortear o trabalho de comunicação e b) modelo híbrido, que representa uma concepção mais consolidada de Política de Comunicação porque, além destes atributos que definem a proposta de comunicação, são explicitadas ações e estratégias voltadas para temas específicos da comunicação organizacional. Em muitos casos, esta proposta indica também produtos complementares a serem elaborados para a implementação da Política, como guias, manuais, pesquisas e metodologias de avaliação do trabalho de comunicação. É comum, nesta proposta, que o documento da Política de Comunicação se faça 
acompanhar de um Plano de Implementação da Política. No modelo padrão, muitas vezes, a construção da Política de Comunicação fica sob a responsabilidade de um grupo restrito de pessoas (profissionais de comunicação e gestores de várias áreas); já na segunda alternativa, além de uma Comissão Central responsável por este trabalho, há o envolvimento dos públicos internos, muitas vezes mediante o sistema de consulta pública, estimulando a participação da comunidade interna no processo de elaboração da Política.

Neste texto, resgatamos para análise quatro documentos de Política de Comunicação elaborados na área pública e que atendem a estes dois formatos ou modelos, pertencentes à Fundação Osvaldo Cruz (Fiocruz), ao Supremo Tribunal Federal (STF), à Empresa Brasileira de Pesquisa Agropecuária (Embrapa) e ao Instituto Federal Goiano de Educação, Ciência e Tecnologia (IF Goiano).

\subsection{Embrapa, um caso emblemático}

A Embrapa pode ser considerada pioneira, na área pública, na construção de uma Política de Comunicação na verdadeira acepção do termo. Ela foi elaborada em 1995 a partir de um diagnóstico organizacional que concluiu pela necessidade de incrementar o processo de relacionamento com os seus públicos estratégicos e de "fortalecimento de sua reputação e de seu reconhecimento institucional" (DUARTE; SILVA, 2007, p. 17).

O objetivo geral da sua Política de Comunicação é "criar e manter fluxos de informação e influência recíproca entre a Embrapa e seus diversos públicos de interesse, subsidiando a definição e implementação de políticas da Empresa, de modo a viabilizar o cumprimento de sua missão". Ela está respaldada em 7 diretrizes básicas (fortalecimento e defesa da marca Embrapa; unicidade do discurso; interação com a sociedade; qualificação da informação; participação interna; parceria e terceirização) e dois focos básicos (o institucional ou corporativo e o mercadológico). (EMBRAPA, 2002, p. 35-81).

A Política de Comunicação da Embrapa contempla também procedimentos e ações estratégicas de comunicação empresarial, alinhados com os objetivos da empresa, buscando em especial articular as ações de comunicação com as voltadas para pesquisa e desenvolvimento e transferência de tecnologia e lista os seus públicos de interesse.

A construção da Política de Comunicação teve a coordenação da Assessoria de Comunicação (ACS) e contou com a participação de um grupo de trabalho e inúmeros colaboradores, não necessariamente da área de comunicação, embora eles se constituíssem em maioria.

Para a construção da Política, a Embrapa contou com a participação de um número expressivo de profissionais de comunicação e de outros setores em reuniões com a presença de dirigentes da empresa, e incluiu, ainda, a presença de um consultor, professor de comunicação da USP com experiência nesta área. Deste processo resultou, ao final, o documento básico da Política 
e, posteriormente, foram elaboradas inúmeros outras publicações, com o objetivo de normatizar posturas e diretrizes específicas, como Manuais de Relacionamento com a Imprensa, de Atendimento ao Cliente, de Editoração, de Eventos, de Identidade Visual, de Redação de Textos Jornalísticos. Desenvolveram-se também iniciativas voltadas para melhorar o atendimento aos públicos, com a criação de SACs on-line (Serviços de atendimento ao cidadão/cliente) e da Ouvidoria e foram realizados treinamentos para a capacitação de profissionais de recepção, atendimento telefônico, transporte e secretaria.

O documento da Política de Comunicação da Embrapa mereceu revisões, a primeira dela em 2002 e que teve, primordialmente, a categorização de todas as modalidades de comunicação previstas na versão original em dois focos principais, a comunicação institucional e a comunicação mercadológica.

\subsection{A Política de Comunicação da Fiocruz}

O documento da Política de Comunicação da Fiocruz foi aprovado pelo Conselho Deliberativo da Fundação em 28 de novembro de 2016 e o seu processo de elaboração inclui consulta interna, aberta a todos os trabalhadores da Fiocruz. Ela parte do pressuposto de que a comunicação é um bem público e reconhece que

Como fator estruturante das relações de poder na sociedade, a comunicação é elemento fundamental dos processos sociais, econômicos e políticos decisivos para a efetivação da democracia e da plena cidadania. Nessa perspectiva, o direito à comunicação é inalienável do direito à saúde, bem como são indissociáveis os campos da comunicação e da saúde coletiva."

A Política de Comunicação da Fiocruz teve como marco o Programa Integrado de Informação e Comunicação, definido em 2002, de que resultou o Livro Verde (Plano Quadrienal 2001-2005) que "defendia informação e comunicação como estruturantes de atividades institucionais, produção de conhecimento e geração de novos processos e produtos, e apontava para o exercício da cidadania e do controle social”. A Fundação reconhecia, de maneira lúcida e contundente, que "a população [...] não quer apenas informações, ela quer se comunicar". (FIOCRUZ, 2002, p. 11)

A Política de Comunicação da Fiocruz estabelece princípios, objetivos gerais e específicos, um conjunto significativo de diretrizes, prevê "efetivo e forte investimento para o desenvolvimento" de políticas, programas e ações de comunicação, bem como indica, explicitamente, a sua estrutura de governança (Conselho Deliberativo, Presidência, Câmara Técnica de Informação e Comunicação, Direção das Unidades, Coordenação de Comunicação Social), além de instâncias de consulta e articulação ou participação. Ela enumera também Políticas, Planos, Programas e com os quais ela está alinhada e Manuais que a subsidiam, como o Manual de Assessoria de Imprensa, Manual de Digitalização, Manual de Mídias Sociais, 
Manual de Redação e Manual de Uso da Lista Fiocruz, todos eles elaborados anteriormente ao documento da Política de Comunicação.

As diretrizes da Política de Comunicação abrangem um número diversificado de temas, aspectos ou questões da comunicação, como o incremento de canais de diálogo e interatividade com as populações envolvidas nas ações da Fiocruz, o mapeamento dos públicos prioritários e o desenvolvimento de estratégias direcionadas a eles, atenção a canais de comunicação de alta capilaridade, como as rádios comunitárias e as redes sociais e também aos voltados para a comunicação interna, esforço de planejamento e monitoramento das ações e estratégias comunicacionais desenvolvidas pela Fundação e muitas outras. Embora estas diretrizes necessariamente não contemplem ações concretas, como as que costumeiramente estão presentes no segundo modelo de Política de Comunicação indicado anteriormente, é importante lembrar que a Fiocruz tem, ao longo do tempo, editado inúmeros manuais direcionados a atividades específicas, como relacionamento com a imprensa ou para atuação nas mídias sociais.

\subsection{A Política de Comunicação do STF}

A Política de Comunicação Social do Supremo Tribunal Federal (BRASIL, 2021) entrou em vigor no dia 12 de abril de 2021 e "integra a missão e o Planejamento Estratégico do órgão", e tem como objetivo "divulgar, de forma clara, didática e acessível, as decisões e os julgamentos do STF, bem como os serviços mantidos pelo Tribunal à disposição do cidadão". (CONSELHO NACIONAL DE JUSTIÇA, 2021). Ela contempla as atividades desenvolvidas por todos os veículos e canais de comunicação do Tribunal como portal de notícias, Rádio e TV Justiça, intranet e redes sociais, sob a gestão da sua Secretaria de Comunicação Social (SCO) e supervisão da Secretaria Geral da Presidência do STF.

A Política de Comunicação do STF enuncia algumas diretrizes gerais, define a Secretaria de Comunicação Social (SCO) como responsável pelo gerenciamento, "de forma estratégica e integrada, as ações de comunicação institucional do STF, a fim de manter a unidade e o caráter impessoal do discurso", bem como pela definição de estratégia, posicionamento, calendário e linha editorial dos seus veículos de comunicação institucional e os perfis em mídias sociais." Indica que a comunicação do STF deve ser acessível a todos os segmentos da sociedade, estipula a abrangência e o espaço de execução das atividades de comunicação" (Assessoria de Imprensa, Comunicação Interna, Design Gráfico e Online, Comunicação Digital e TV e Rádio Justiça). Ela define também requisitos e responsabilidades e dedica espaço especial para o Comitê de Imprensa, espaço destinado aos jornalistas que fazem a cobertura do STF.

O documento da Política de Comunicação do STF segue o modelo padrão e, portanto, não incorpora ações concretas voltadas para atividades ou públicos específicos, nem se refere à necessidade de elaboração de guias, manuais, auditorias ou diagnósticos, permanecendo, portanto, em um plano bem geral. O STF já dispõe de uma Política de Uso das Redes Sociais, 
ainda que descrita de maneira sucinta. (BRASIL, 2020).

\subsection{A Política de Comunicação do IF Goiano}

A Política de Comunicação do Instituto Federal Goiano (IF Goiano) entrou em vigor em 2020 e o documento que a legitima segue, basicamente, o modelo híbrido, a exemplo do que acontece para a maioria dos Institutos Federais e para algumas universidades estaduais e federais que já dispõe deste instrumento estratégico de gestão.

O documento da Política de Comunicação do IF Goiano está estruturado em 14 capítulos que abrangem temas relevantes da área e que foram foco de discussão em reuniões realizadas em 2020 com a participação de profissionais, gestores, servidores e mesmo de especialistas em comunicação de Goiás e de outros Estados da Federação. Além de incluir diretrizes, posturas e estratégias, define ações a serem realizadas com objetivos específicos (relacionamento com a mídia, atuação nas mídias sociais, gestão de crise, comunicação interna, divulgação da pesquisa, ensino, extensão e inovação, promoção e realização de eventos, dentre outros) indica produtos (guias, manuais, auditorias, diagnósticos, sistemas de avaliação em comunicação) a serem desenvolvidos para qualificar a interação do Instituto com os seus públicos estratégicos. (INSTITUTO FEDERAL GOIANO, 2020).

A construção da Política de Comunicação do IF Goiano caracterizou-se por um processo de construção coletiva, pela consulta à comunidade interna, estimulada permanentemente à participação, e contou com o assessoramento técnico de um especialista da área, com experiência no desenvolvimento de trabalhos similares em outras instituições educacionais e de pesquisa. Todo o trabalho de construção da Política de Comunicação do IF Goiano foi conduzido por uma Comissão de Comunicação, integrada por profissionais da área e de outros setores, gestores, servidores, sob a liderança da Diretoria de Comunicação Social (DICOM).

O documento da Política de Comunicação do IF Goiano tem como produto complementar o Plano de Implementação da Política de Comunicação - que indica as ações a serem realizadas a curto, médio e longo prazos, tendo em vista tornar as diretrizes efetivas e assumidas por todos os públicos internos do Instituto.

\section{O Parlamento, comunicação pública e comunicação política}

Embora não seja o foco deste artigo analisar e debater a articulação entre a comunicação pública e a comunicação política, que, de alguma forma, caracterizam a prática comunicacional do Poder Legislativo, é fundamental ressaltar que estas dimensões estão sempre presentes e que dialogam permanentemente.

É imperioso identificar, no caso da Câmara dos Deputados, do Senado Federal, das Assembleias Legislativas e mesmo das Câmaras de Vereadores, que as atividades de comunicação são instrumentalizadas a partir de uma tensão entre o interesse público, o interesse privado e, 
inclusive, o interesse pessoal e de grupos organizados (os partidos políticos, as associações da sociedade civil, dentre outros).

O esforço de construir uma Política de Comunicação para uma determinada casa legislativa deve, obrigatoriamente, contemplar estas questões porque, muitas vezes, os protagonistas dessa comunicação (os políticos, os parlamentares) mantêm vínculos com as instâncias que os elegeram, sejam elas constituídas pelos cidadãos que contribuíram com o seu voto, pelas empresas ou entidades que financiaram as campanhas, ou mesmo os partidos políticos que detêm uma plataforma, um programa aos quais eles são obrigados a se submeterem.

O esforço de comunicação do Poder Legislativo não se reduz aos canais institucionais por ele utilizado para se relacionar com determinados públicos estratégicos e com a sociedade, mas inclui todo o trabalho realizado para o debate dos temas nacionais, regionais e locais que são de interesse público que acontece, recorrentemente, nas casas legislativas (sessões plenárias, comissões) e que se estende à manifestação dos partidos e dos seus representantes junto à mídia e aos múltiplos "espaços de conversa" na sociedade, dentre os quais se destacam, nos últimos anos, as mídias sociais.

É imperioso reconhecer que a comunicação das casas legislativas brasileiras não está respaldada por instrumentos competentes de gestão da comunicação, como as Políticas de Comunicação, efetivamente sistematizadas e derivadas de um consenso, e que, portanto, tem como característica básica a ausência de unicidade e de diretrizes que são compartilhadas por todos os seus representantes.

Até o momento em que escrevemos este artigo, apenas uma casa legislativa, a Assembleia Legislativa de Minas Gerais (ALMG), dispunha de uma Política de Comunicação, construída em 2017, e que, para sua elaboração, levou em conta dois objetivos finalísticos: "ampliar e aprimorar a participação da sociedade nas atividades do Legislativo" e "consolidar-se como ponto de convergência do poder público e da sociedade na discussão das estratégias e políticas públicas para o desenvolvimento do Estado" (2017, p. 4).

A Política de Comunicação da Assembleia de Minas Gerais define como seu propósito principal contribuir para o cumprimento dos objetivos institucionais, colaborando, assim, para o alcance da missão do Poder Legislativo mineiro. As diretrizes, os princípios e os mecanismos de gestão dessa política "visam efetivar um modelo relacional de comunicação integrada, em que o foco do planejamento e da produção comunicativa da ALMG esteja dirigido aos públicos da instituição, com suas características, necessidades e expectativas." Ela se estrutura em dois eixos conceituais, os princípios da gestão da reputação e os princípios da comunicação pública. Ela entende como reputação de uma organização "a representação coletiva construída ao longo dos anos, de conteúdo ativo e capaz de modular os relacionamentos entre a instituição e seus múltiplos públicos, e de impactar resultados futuros" e assume como propósito fundamental da comunicação pública "direcionar os esforços da comunicação institucional para a legitimidade do 
interesse público. Nesse sentido, torna-se central a busca da clareza na divulgação das informações, favorecendo o amplo entendimento que fomenta o debate e a participação cidadã" (ASSEMBLEIA LEGISLATIVA DE MINAS GERAIS, 2017, p. 5-6).

A Política de Comunicação da Assembleia Legislativa de Minas define os eixos de atuação, a sua abrangência, e enumera os atributos da sua comunicação. Lista também os seus públicos prioritários, explicita as suas diretrizes, bem como indica que a Diretoria de Comunicação Institucional (DCI) será a instância responsável pela sua gestão, apoiada em um sistema de Governança que visa "permitir o contínuo monitoramento das iniciativas de comunicação em andamento no sistema e, ao mesmo tempo, abrir espaço para inovações estratégicas." (ASSEMBLEIA LEGISLATIVA DE MINAS GERAIS, 2017, p. 14).

É importante destacar que as diretrizes Política de Comunicação da Assembleia Legislativa de Minas são bastante gerais, típicas do primeiro modelo ou formato definido anteriormente, e que não se reporta a temas ou estratégias específicas, como, por exemplo, o relacionamento com a mídia, a atuação nas mídias sociais, a comunicação interna, dentre outras, o que, de imediato, evidencia a necessidade de documentos complementares que possam dar conta dessas situações.

Temos conhecimento, porque este fato se tornou público (está registrado na $W e b$ ), que o Conselho Consultivo de Comunicação da Câmara dos Deputados aprovou, em 26 de novembro de 2019, a sua Política de Comunicação Social que foi, inclusive, submetida à consulta pública, recebendo sugestões da sociedade. Ocorre, no entanto, que, a partir daí, o processo de aprovação pela Mesa Diretora não se completou, em função da troca Secretário de Comunicação em 2020 e outras mudanças posteriores, de tal modo que até o momento de produção deste artigo, a Política de Comunicação não está em vigor. É razoável admitir que, com as alterações importantes ocorridas na Câmara dos Deputados (Presidência da Câmara, Mesa Diretora, e mesmo no Conselho de Comunicação) que a Política de Comunicação venha a ser rediscutida e que o texto original possa ser revisto.

De qualquer forma, pela consulta que pode ser feita ao texto inicialmente aprovado, a Política de Comunicação da Câmara dos Deputados abrangia princípios, objetivos, diretrizes, previa o mapeamento dos públicos com os quais deveria interagir, mas assumia como pressuposto que deveria se comunicar com todos os cidadãos e indicava requisitos para que a comunicação desta casa legislativa poderia se tornar efetiva. Dentre eles, enumerava a "garantia de recursos para cumprir os objetivos e diretrizes, o desenvolvimento ou aquisição de tecnologia atualizada, estabelecimento de instrumentos de planejamento e capacitação, atualização e especialização de servidores" (BRASIL, 2019).

É ilustrativo citar, no caso desta proposta de Política de Comunicação Social, elaborada pelo Conselho Consultivo de Comunicação da Câmara dos Deputados, a explicitação de algumas posturas ou comportamentos não aceitos, previstos nos dois artigos que integram o capítulo 
intitulado "Vedações":

Artigo $8^{\circ}$ É vedado aos profissionais da Câmara dos Deputados, na produção de conteúdos institucionais:

I) Exprimir opinião própria favorável ou contrária acerca de qualquer proposta legislativa;

II) Aceitar pagamento ou vantagem indevida.

Artigo $9^{\circ}$ A comunicação da Câmara dos Deputados não publica conteúdo de caráter eleitoral, de promoção pessoal de autoridade ou de servidor público, de propaganda com objetivo religioso ou comercial, nem favorece posições políticas". (BRASIL, 2019)

Essas vedações devem ser entendidas como naturais na elaboração de políticas de comunicação de instituições públicas, em especial no Parlamento brasileiro, porque manifestam a imperiosa necessidade de não se confundir o interesse público com o interesse privado e de primar pela ética na gestão da comunicação institucional.

\section{A construção de uma Política de Comunicação para o Parlamento}

A construção de uma Política de Comunicação deve obedecer a uma dinâmica e a uma metodologia com características singulares e percorrer, obrigatoriamente, uma série de etapas. Este processo será gerenciado por uma Comissão (por exemplo, um Conselho Consultivo de Comunicação) que deve ser integrada por profissionais de comunicação e gestores e profissionais de várias áreas, com a supervisão, direta ou indireta, de representantes da alta administração (Diretorias, Presidência). Esta Comissão acompanhará todo o processo de discussão da Política e poderá permanecer à frente do processo de construção da Política de Comunicação até a sua implementação.

A Comissão definirá, a princípio, o modelo de documento (padrão ou híbrido) a ser adotado na construção da Política de Comunicação, assim como o tempo necessário para a sua consolidação. No caso da adoção do modelo híbrido, que, além de diretrizes e princípios gerais, se debruça sobre questões básicas da comunicação organizacional (relacionamento com a mídia, presença e atuação nas mídias sociais, gestão da comunicação em situações de crise, gestão da marca institucional, dentre outras), como fez o Instituto Federal Goiano, é importante estabelecer um calendário de reuniões (presenciais ou virtuais) para estabelecer as estratégias e posturas definidas pela organização para estas atividades e prever a participação de pessoas (profissionais e gestores) que podem contribuir para este debate.

De imediato, é fundamental ter presente, no início dos trabalhos, o conceito de Comunicação Organizacional a ser praticado, evitando-se o equívoco comum de assumir a comunicação de uma organização como um sistema unilateral de transmissão de informações. Ao mesmo tempo, é necessário entender o processo de comunicação em suas dimensões básicas, caracterizadas pela integração e pelo caráter estratégico. 
Uma Política de Comunicação competente e articulada tem, como tarefa inicial, a definição dos públicos estratégicos, visto que todo esforço de comunicação objetiva, primordialmente, a interação com os stakeholders, os públicos que, direta ou indiretamente, impactam a organização e são impactados pela sua atuação. Tais públicos deverão ter seus perfis, suas demandas e expectativas conhecidos e regularmente monitorados, de modo a permitir uma interação saudável e produtiva.

A Política de Comunicação está respaldada em objetivos, valores, atributos, princípios que estão sintonizados com a gestão e a cultura organizacional e, quase sempre, decorre de uma demanda prevista no Planejamento Estratégico.

Em geral, os processos de construção de uma Política de Comunicação incorporam, no momento inicial, a elaboração de um amplo diagnóstico da situação atual da comunicação interna e externa da organização ou empresa, que abrange, obrigatoriamente, a análise da eficácia dos canais de relacionamento, utilizados para a divulgação dos fatos e realizações institucionais e para a interação com os públicos estratégicos.

O modelo adotado (padrão ou híbrido) para o documento da Política de Comunicação irá nortear todo o processo de construção, definindo as pessoas a serem mobilizadas e o período de sua execução. Em todos os casos, é recomendável, particularmente em instituições públicas, como o Parlamento, que este processo seja dialógico, que contemple todos os envolvidos como protagonistas, de tal modo que o documento da Política seja resultado de construção coletiva, com consulta pública à comunidade interna e externa.

Partindo-se do pressuposto de que a Política de Comunicação não se encerra com a produção e aprovação do documento que a legitima, é indispensável dedicar atenção especial ao processo de sua implementação. As diretrizes, ações, estratégias definidas pela Política de Comunicação devem ser amplamente divulgadas e estar permanentemente acessíveis para os públicos internos e externos.

O trabalho de implementação da Política de Comunicação deve ser gerenciado por uma Comissão, que pode inclusive ser a mesma que participou da sua elaboração, com o objetivo de identificar se as diretrizes estão sendo cumpridas à risca.

A Política de Comunicação, como vimos anteriormente, é datada e, por isso, deve ser revista e atualizada ao longo do tempo, em função de mudanças que normalmente ocorrem na organização, na sociedade e mesmo no próprio universo da comunicação, pelo surgimento de novas técnicas, estratégias e recursos que, depois de devidamente analisados e debatidos, poderão ser incorporadas.

\section{Conclusão}

A Política de Comunicação deve ser assumida sempre como um instrumento estratégico de gestão que tem como objetivo subsidiar todas as ações e processos de comunicação realizados 
por uma organização para o relacionamento com os seus públicos de interesse e com a sociedade.

No Brasil, a construção de Políticas de Comunicação pelas casas legislativas tem sido relegada a um segundo plano, o que significa, em termos práticos, que a comunicação não é percebida como um fator estruturante estratégico. Desta forma, apesar de um conjunto formidável de atividades desenvolvidas pelo Parlamento, não há, institucionalmente, um esforço no sentido de definir e padronizar diretrizes que orientam o seu planejamento e execução, o que compromete a eficácia das ações e estratégias e abre brechas para a ocorrências de situações de tensão ou instabilidade.

A realização de um benchmarking junto a instituições da área pública que já dispõem de Políticas de Comunicação pode indicar caminhos a serem trilhados pelas casas legislativas e inspirar iniciativas inovadoras.

É fundamental reconhecer que a convergência entre a comunicação pública e a comunicação política, que constituem dimensões importantes do trabalho de comunicação do Parlamento, se efetivamente articuladas para a consolidação da cidadania e o debate democrático, aponta para uma imperiosa necessidade: o processo de construção de uma Política de Comunicação deve ser fruto de construção coletiva, com a participação efetiva da sociedade.

Uma Política de Comunicação para o Parlamento brasileiro deve privilegiar o interesse público, e não permitindo que a comunicação possa estar a serviço de grupos ou pessoas. Deve estar comprometida com a transparência, a ética e o respeito à diversidade de ideias e opiniões, implementando canais de relacionamento e buscando definir, permanentemente, mecanismos de interlocução com a sociedade brasileira.

\section{Referências}

BRASIL. CÂMARA DOS DEPUTADOS. Política de Comunicação. Brasília, DF? Câmara dos Deputados. 2019. Disponível em: https://www2.camara.leg.br/comunicacao/conselhode-comunicacao/politica-de-comunicacao. Acesso em 01/04/2021.

CONSELHO NACIONAL DE JUSTIÇA. Entra em vigor a Política de Comunicação Social do Supremo Tribunal Federal. CNJ, Conselho Nacional de Justiça, Brasília, 2021. Disponível em: em: https://www.cnj.jus.br/entra-em-vigor-a-politica-de-comunicacao-social-do-supremotribunal-federal/. Acesso em 20/04/2021.

DUARTE, Jorge; SILVA, Heloisa Dias da. Política de Comunicação e gestão empresarial: a experiência da Embrapa. Organicom. São Paulo, v. 4, n. 6, 2007.

EMBRAPA. Política de Comunicação. 2a Ed. Revista e ampliada. Brasília/DF, 2002.

FIOCRUZ. Política de Comunicação da Fiocruz. Rio de Janeiro: FIOCRUZ, 2017. 38 p.

FIOCRUZ. Programa Integrado de Informação e Comunicação da Fiocruz/Fundação Oswaldo Cruz. Rio de Janeiro, 2002.

INSTITUTO FEDERAL GOIANO. Política de Comunicação. Goiânia,: IF GOIANO, 2020. 205 p. Disponível em:

https://suap.ifgoiano.edu.br/media/documentos/arquivos/Pol\%C3\%ADtica_de_Comunica\%C3 \%A7\%C3\%A3o_FINAL.pdf. Acesso em 12/02/2021. 
NORI, Walter; VALENTE, Célia. Portas Abertas. São Paulo: Círculo do Livro, 1990.

BRASIL. Supremo Tribunal Federal.. Política de uso de redes sociais. Brasília. 2020.

Disponível em: http://portal.stf.jus.br/textos/verTexto.asp?servico=politicausoredessociais. Acesso em 19/04/2021.

BRASIL. Supremo Tribunal Federal. Política de Comunicação Social. Diário da Justiça Eletrônico. Brasília. Número 68, 12/04/2021. Disponível em:

http://www.stf.jus.br/ARQUIVO/NORMA/RESOLUCAO730-2021.PDF. Acesso em 20/04/2021.

Artigo submetido em: 2021-04-30

Artigo aceito em: 2021-05-06 